\title{
Laparotomia paramediana oblíqua para ovariectomia em uma égua: relato de caso
}

${ }^{[a]}$ Hospital Anclivepa, São Paulo, SP, Brasil

[b] Instituto Municipal de Medicina Veterinária Jorge Vaitsman, Rio de Janeiro, RJ, Brasil

[c] Universidade Iguaçu (UNIG), Itaperuna, RJ, Brasil

*Autor correspondente

e-mail: mv.guilhermegraaf@yahoo.com.br

Resumo

O proprietário de um equino da cidade de Quissamã/RJ buscou avaliação oftalmológica, já que o mesmo apresentava manchas brancas em ambos os olhos, a fim de obter um diagnóstico e saber das condições visuais do animal. Esse trabalho objetiva descrever o caso clínico de um equino macho e mestiço de 8 anos de idade, diagnosticado com leucoma bilateral associado com membrana pupilar persistente. Realizou-se uma avaliação oftalmológica em que, através da transiluminação direta, observou-se a presença de opacidade corneana bilateral, porém com resposta positiva aos testes de ameaça e movimento, e de diversas membranas pupilares indo de encontro ao endotélio corneano (sinéquia anterior), além de formação de leucoma secundário no contato entre as membranas e o endotélio. A confirmação clínica do diagnóstico foi obtida com o uso da lâmpada de fenda. 0 leucoma é uma condição congênita que não costuma evoluir, mas que pode acarretar danos visuais ao animal. No caso aqui relatado, constatou-se a ocorrência de leucoma bilateral posicionado no centro dos campos visuais.; no entanto, ambos os olhos se mostravam visuais. A constatação da perfeita acuidade visual do animal se mostrou relevante por se tratar de uma montaria de criança. A literatura não sugere tratamento nesses casos porque as membranas pupilares podem ser vascularizadas e tanto o descolamento cirúrgico das membranas, por sua característica invasiva, quanto o uso de midriáticos, pela tensão causada nas membranas, podem causar rupturas e, por consequência, levar a hematomas e hemorragias intraoculares. Apesar do equino apresentar leucoma bilateral associado com membrana pupilar persistente, sua visão não estava comprometida. Considerando-se os riscos envolvidos em possíveis interferências, não sugeriu-se nenhum tratamento pois esta abordagem se alinha com o referido na literatura. Esse trabalho tem o apoio da Prefeitura Municipal de Quissamã/RJ.

Palavras-chave: Membrana pupilar. Sinéquia. Córnea. 